Accident and

Emergency

Department, St James's University

Hospital, Beckett

Street, Leeds

LS9 7TF

Correspondence to: Dr McGowan, Dean of the Faculty of Accident and

Emergency Medicine (mcgowns@cwcom.net)

Department of Accident and Emergency Medicine, Poole General Hospital, Longfleet Road, Poole, Dorset BH15 2JB

Correspondence to:

Dr Robinson

(poppabearbb@hotmail.com) Accepted 29 February 2000
The following article was initially presented at the Speciality Examination for Fellowship of the Faculty of Accident and Emergency Medicine. The examiners at that diet awarded it a high score.

It is reproduced here as an example of what the Education and Examination Board of the Faculty believe a clinical topic review should be.

The purpose of the clinical topic review in the Fellowship Examination is to allow the candidate an opportunity to demonstrate their competence in selecting a topic, formulating a question, conducting a literature search, appraising individual papers, analysing their content and reducing the material to writing.
Each applicant for the examination is required to submit two clinical topic reviews, each of about 2500-3000 words. The clinical topic reviews must be supplied with the other necessary papers at the time of submitting an application for entry to the examination.

Advice is often sought as to how much time a candidate should lay aside for the preparation of each clinical topic review and it is hoped that this excellent example will allow prospective candidates some insight in to the quality and volume of work that is required.

\title{
The focused trauma ultrasound examination. Can, and should, accident and emergency physicians in the UK acquire this skill?
}

ALASTAIR McGOWAN

\section{Neil Robinson}

The use of ultrasonography for the investigation of urgent diagnostic problems has been used widely for almost 40 years. During the past decade ultrasonography, by nonemergency department physicians, has achieved a primary role in Europe and Asia in the investigation of emergent conditions such as abdominal and thoracic trauma. ${ }^{1-6}$ In the United States the use of this bedside modality by emergency physicians (EPs) has expanded rapidly in recent years with more than 100 emergency departments providing an ultrasound service delivered by EPs. ${ }^{7}$ A fellowship programme in emergency ultrasonography and model curriculum for EP training in ultrasound have been produced. ${ }^{8}$ This is fully supported by the American College of Emergency Physicians (ACEP) and the Society for Academic Emergency Medicine (SAEM) who produced their position statements on the subject in $1991 . .^{910}$

The crux, of the EPs use of ultrasound in trauma, is that by placement of the ultrasound probe over six anatomical areas (see fig 1) it is possible to answer highly focused questions yielding useful diagnostic information as quickly as possible. It is expected that the investigation should take 5-10 minutes to complete and be carried out, during trauma resuscitation, at the patient's bedside.

In traumatised patients there are three primary applications for its use in the emergency department:

Is there intra-abdominal free fluid?
Is there a pericardial effusion?

Is there evidence of a haemothorax?

It is clear that these are potentially life threatening problems and that timeliness is important. It has been shown that bedside

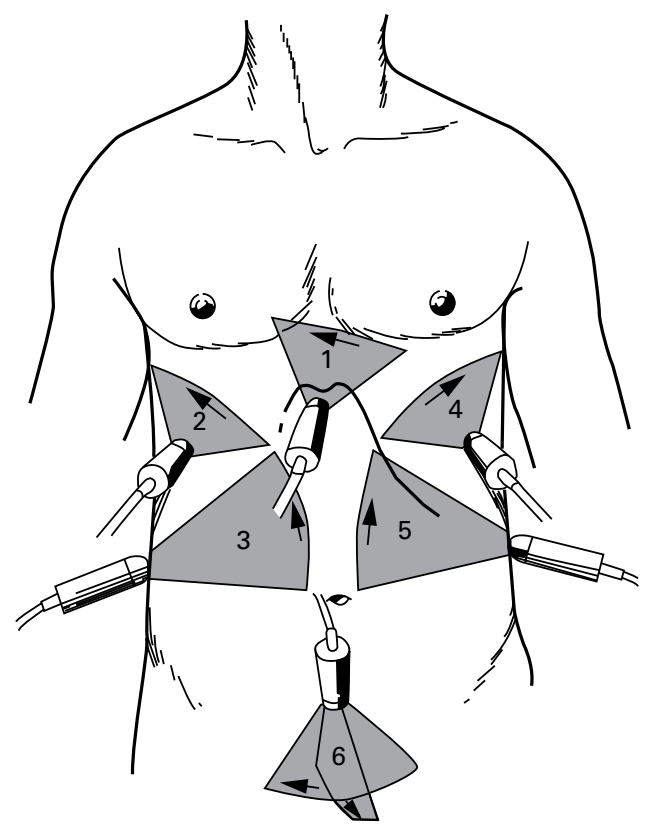

Figure 1 Probe placement in the focused trauma ultrasound examination. 
Table 1 A summary of the valid papers identified. LR is the likelihood ratio for a positive (+) or negative (-) result

\begin{tabular}{|c|c|c|c|c|c|c|}
\hline $\begin{array}{l}\text { Author, date, } \\
\text { country }\end{array}$ & Patient group & Study type & Gold standard & $L R+v e$ & $L R-v e$ & Study weaknesses \\
\hline $\begin{array}{l}\text { Jehle et al, } \\
\text { 1993, USA }\end{array}$ & $\begin{array}{l}11 \text { adult blunt trauma } \\
\text { patients. }\end{array}$ & $\begin{array}{l}\text { Retrospective, blinded, diagnosis } \\
\text { of intra-abdominal free fluid } \\
\text { (IAFF). }\end{array}$ & Laparotomy or DPL. & 13.66 & 0.19 & $\begin{array}{l}\text { Small numbers. } 33 \text { other } \\
\text { patients scanned but gold } \\
\text { standard not applied. }\end{array}$ \\
\hline \multirow{3}{*}{$\begin{array}{l}\text { Ma et al, } 1995, \\
\text { USA }\end{array}$} & \multirow{3}{*}{$\begin{array}{l}245 \text { adult blunt or } \\
\text { penetrating trauma } \\
\text { patients. }\end{array}$} & \multirow{3}{*}{$\begin{array}{l}\text { Prospective, blinded, } \\
\text { observational, diagnosis of IAFF, } \\
\text { pericardial fluid (PCF) or pleural } \\
\text { fluid (PLF). }\end{array}$} & Laparotomy, CT or & IAFF 86 & 0.14 & \\
\hline & & & DPL. Thoracotomy or & PCF 100 & 0 & \\
\hline & & & echocardiography. & PLF $>100$ & 0.04 & \\
\hline $\begin{array}{l}\text { Ingeman et al, } \\
\text { 1996, USA }\end{array}$ & $\begin{array}{l}97 \text { adult blunt trauma } \\
\text { patients. }\end{array}$ & $\begin{array}{l}\text { Prospective, blinded, } \\
\text { observational, diagnosis of IAFF }\end{array}$ & $\begin{array}{l}\text { Laparotomy, CT or } \\
\text { DPL. }\end{array}$ & 18.75 & 0.26 & \\
\hline $\begin{array}{l}\text { Ma et al, 1997, } \\
\text { USA }\end{array}$ & $\begin{array}{l}245 \text { adult blunt or } \\
\text { penetrating trauma } \\
\text { patients. }\end{array}$ & $\begin{array}{l}\text { Retrospective analysis of previous } \\
\text { study. comparing initial CXR and } \\
\text { ultrasound in diagnosing } \\
\text { haemothorax. }\end{array}$ & $\begin{array}{l}\text { Chest tube } \\
\text { thoracostomy or CT. }\end{array}$ & $>100$ & 0.04 & $\begin{array}{l}\text { Retrospective study, tagged } \\
\text { on to previous study. }\end{array}$ \\
\hline $\begin{array}{l}\text { Shackford et al, } \\
\text { 1999, USA }\end{array}$ & $\begin{array}{l}241 \text { adult blunt or } \\
\text { penetrating trauma } \\
\text { patients. }\end{array}$ & $\begin{array}{l}\text { Prospective, observational. } \\
\text { Abilities of "rookie" EP } \\
\text { sonographers at diagnosing IAFF }\end{array}$ & $\begin{array}{l}\text { Laparotomy, DPL, CT } \\
\text { or serial physical } \\
\text { examinations. }\end{array}$ & 34 & 0.33 & $\begin{array}{l}\text { Blinding is not explicit only } \\
\text { implied. }\end{array}$ \\
\hline
\end{tabular}

ultrasonography has helped to increase the efficiency and safety of patient management by reducing the time taken to identify these conditions. ${ }^{11-16}$

\section{Objective}

Can, and should, accident and emergency (A\&E) department physicians in the UK follow the American moves with respect to carrying out focused trauma ultrasound examinations?

\section{Methods}

1 A comprehensive literature search was carried out using the following:

(a) Medline 1966- 7/1999 and EMBASE. 1988-7/1999

Terms used: (exp Emergency Medicine OR Emergency Physician\$.mp OR Accident and emergency Physician OR Accident and emergency physician\$.mp) AND (*ultrasonography OR ultrasound\$.mp) AND ( ${ }^{\star}$ multiple trauma OR exp abdominal injuries OR exp wounds, non penetrating OR exp wounds, penetrating OR abdominal trauma $\$ \mathrm{mp}$ ) OR (exp heart injuries OR exp thoracic injury OR exp wounds, non penetrating OR exp wounds, penetrating OR thoracic trauma $\$$ mp. LIMIT to human and english language.

(b) The Cochrane library

(c) A bibliographical search of those papers identified by the above searches was done.

(d) Personal communication with leading clinicians in the field in the United States.

The purpose of the search was to identify all papers that determined the diagnostic performance of EPs using ultrasound on patients presenting with abdominal and/or thoracic trauma. Then see if this performance was comparable to that of trained sonographers and finally examine the training in ultrasound undertaken by these EPs.

2 Those papers identified were appraised in the manner recommended by the evidence based medicine group using the following criteria ${ }^{17}$ :

(a) Was there an independent, blind comparison with a reference ("gold") standard of diagnosis? (b) Was the diagnostic test evaluated in an appropriate spectrum of patients?
Table 2 Sensitivities and specificities calculated from the papers

\begin{tabular}{lll}
\hline Condition & Sensitivity (\%) & Specificity (\%) \\
\hline Intra-abdominal free fluid & $68-86$ & $93.9-99$ \\
Pericardial effusion & 100 & 99 \\
Pleural fluid & $96-97$ & 100
\end{tabular}

(c) Was the reference standard applied regardless of the diagnostic test result?

Only those papers determined to be valid were included in this review.

3 The frequency of patients presenting to UK $\mathrm{A} \& \mathrm{E}$ departments with conditions that may benefit from a focused trauma ultrasound examination was determined using the most up to date and accurate database available (The UK Trauma Audit and Research Network).

(4) The frequency with which focused trauma ultrasound examinations would be used per 1000 new patients attending UK A\&E departments was then estimated.

\section{Results}

(1) Seventeen papers were found of which 12 were irrelevant to the question posed or of insufficient quality for inclusion. Five valid papers were identified. ${ }^{18-22}$ See table 1 .

It is also possible to summarise the relevant sensitivities and specificities calculated from the papers. These are shown in table 2 .

(2) Frequency data for haemoperitoneum and haemopericardium.

The following are the raw data extracted from the UK Trauma Audit and Research Network database. It is taken from the 34 hospitals that have sent data continuously over the period from 1992-1996 except patients transferred out to other hospitals. In an attempt to capture all the possible cases where focused trauma ultrasound may have been of value and used, if it were available, the data were collected as follows:

The AIS is the Abbreviated Injury Score. A full list of codes is available from the Trauma Network UK.

(a) Numbers of cases with abdominal trauma (AIS codes 515000-55000) presenting in the following:

Group 1 Those with multiple injuries.

Group 2 Where the abdominal trauma is the only injury $+/-$ minor injuries in other body areas. 
Table 3 Number of cases in each group

\begin{tabular}{lllllll}
\hline & 1992 & 1993 & 1994 & 1995 & 1996 & Total \\
\hline A (Total groups 1+2) & 439 & 344 & 487 & 457 & 391 & 2118 \\
B (Total groups 3+4) & 1063 & 1233 & 1252 & 1486 & 1202 & 6236 \\
C & 87 & 72 & 134 & 141 & 111 & 545 \\
D & 461 & 498 & 668 & 752 & 556 & 2935 \\
\hline
\end{tabular}

Table 4 Frequency of presentation

\begin{tabular}{lll}
\hline Group & Per 1000 new patients & In whole patient equivalents \\
\hline A & 0.25 & $1: 4000$ \\
B & 0.73 & $3: 4000$ \\
C & 0.064 & $1: 15000$ \\
D & 0.34 & $1: 3000$ \\
\hline
\end{tabular}

(b) Numbers of cases with chest trauma (AIS codes 415000-46000)

Group 3 Those with multiple injuries.

Group 4 Where the chest trauma is the only injury $+/-$ minor injuries in other body areas.

A further sub-selection was carried out in an attempt to identify those patients in whom retrospectively, a focused trauma ultrasound examination would have been more likely to have yielded a positive result.

(c) Haemoperitoneum.

AIS code Description of code

515098 Actual code for haemoperitoneum. $541814 / 541840$ Hepatic and splenic capsular injuries. 541824-541830

(AIS 3+) Penetrating injury to the abdomen

(d) Haemopericardium.

AIS code Description of code

441699 Pericardial injury not further specified

420299 Thoracic aorta injury not further specified. 420202-420218Increasing severity of thoracic aorta injury. 416000-416008Penetrating injury to the chest

(AIS 3+)

The number of cases in each group is shown in table 3.

(3) The total number of new A\&E patients between 1 January 1992 and 31 December 31 1996 attending the 34 hospitals is estimated, as the actual number of new attendances was not captured on the database until 1997. However, by using the actual figure for 1997 for these hospitals (1 935 200) and extrapolating back to 1992 by discounting at a rate of $4 \%$ per year (the approximate mean rise in new patients per year nationally) it is possible to approximate the total number of new patients who presented during this five year period.

This was calcualted as 8574000

Using this figure it is possible to calculate the frequency of presentation of these cases. This is shown in table 4.

So the widest capture of patients on the database where focused trauma ultrasound examination in abdominal and chest injuries may have been of value, and used if it were available is $\mathrm{A}+\mathrm{B}$.

1 case per 1000 new patients

Those patients in whom, retrospectively, a focused trauma ultrasound examination would have been more likely to have yielded a positive result is $\mathrm{C}+\mathrm{D}$.

1 case per 2500 new patients

\section{Discussion}

The focused trauma ultrasound examination, whether performed and interpreted by radiologists or EPs, is a highly reliable test to screen for haemoperitoneum or haemopericardium after blunt or penetrating trauma. There has been a lot of published work looking at the diagnostic accuracy of another group of emergency clinicians, namely trauma surgeons, carrying out focused trauma ultrasound examinations. A collective series of 4941 trauma patients showed that they attained an overall sensitivity and specificity of $93.4 \%$ and $98.7 \%$ respectively. ${ }^{23}$ These results are all the more impressive when one appreciates that there is no official fellowship training and credentialing programme available in focused trauma ultrasound for surgeons in the US.

This review has shown that, except in one study that looked specifically at the first 20 scans performed by "trainee" EP sonographers attaining a sensitivity of $68 \%$ for the detection of $\mathrm{IAFF}^{22}$ the diagnostic performance of trained EPs in focused trauma ultrasound is comparable to that of trained sonographers. Figures quoted for their performance in the literature range from $89-100 \%$ sensitive and $96-100 \%$ specific. $^{235}$ The training in ultrasound undertaken by the EPs in the seven studies did vary considerably. There were, however, some features common to all the training programmes:

(A) A period of didactic instruction. (1-40 hours)

(B) A number of practical demonstrations and videos.

(C) Hands on instruction. (1-20 hours)

(D) Supervised patient studies. (1-20)

This training seems to be at loggerheads with the American Institute of Ultrasound in Medicine (AIUM) who, as the major professional society devoted to ultrasound, recommend a minimum of three months of supervised training, 100 hours of American Medical Association CME activity, and 300 ultrasound examinations before a physician sonographer could be considered competent enough to perform abdominal sonography. ${ }^{24} \mathrm{~A} \& \mathrm{E}$ physicians in the United Kingdom contemplating training in ultrasound face a similar problem. In 1997, following the recommendations of a working party on the subject, the Royal College of Radiologists published their guidelines for the training of medical non-radiologists. ${ }^{25}$ Based on a modular format they recommend a basic training of 15 hours of tuition on the theoretical aspects of ultrasound followed by 300 examinations in the first practical module. Further modules can be added but require a further 150 examinations per module, each module referring to a different anatomical region or organ system. Their inference is that they consider it necessary to complete 450 examinations before a UK EP can use ultrasound unsupervised to diagnose IAFF, pericardial or pleural fluid. There is, however, no data in the scientific literature to substantiate the American or British recommendations. Nei- 
ther group seem to be familiar with the concept of the clinically "focused" examination and how it differs from the more comprehensive sonogram as it is not mentioned in either of their publications. Clearly, the guidelines for other specialties also include many topics not relevant to emergency medicine. Consequently, the SAEM task force recommended that general training in emergency department ultrasound should consist of 40 hours of instruction and 150 supervised examinations and that $>50 \%$ of these should be on clinically indicated patient studies. ${ }^{8}{ }^{26}$ Recently published evidence has, however, suggested that the learning curve in using ultrasound to detect haemoperitoneum is such that EPs need only do 10 supervised exams by which time their error rate falls from $17 \%$ to $5 \%{ }^{22}$ This suggests that the numbers recommended by the SAEM are still excessive.

The other issues seldom mentioned in the US literature are those of quality assurance and skill maintenance in relation to EPs performing focused trauma ultrasound examinations. The very nature of the skills required to undertake ultrasound - that is, a combination of psychomotor and cognitive skills-explains why the examinations are so operator dependent and why quality assurance programmes are so important. Methods of quality assurance vary between individual institutions. Common features do, however, exist. Firstly, the documentation, hard copies and image quality produced by the EPs is reviewed. The results are then fed back to each individual practitioner (personal communication). Secondly, a number of studies done by each EP is compared with pre-set "gold standards" and reviewed by experienced seniors in emergency medicine, radiology or both. ${ }^{27}$ Thirdly, "critical incident monitoring" is used within some emergency departments to identify any areas of concern with respect to the ultrasound examinations of any particular physician and any one not attaining the agreed standard is offered further training and supervision (personal communication).

The reason that I chose to include the raw frequency data in this topic review is that the maintenance of skills is clearly related to the frequency of presenting cases - the more you do the better you become. The data, from the Trauma Network database, indicate a frequency of 1 case per 1000 new patients attending UK $\mathrm{A} \& \mathrm{E}$ departments. This approximates to one case per week undergoing an ultrasound examination for the exclusion of intraabdominal free fluid and/or pericardial tamponade in an average UK A\&E department. This rate of presentation may be sufficient for one practitioner to maintain his or her skills but the issue is confounded further when you consider having to provide the service 24 hours per day and the total number of cases is divided between all those clinicians participating in the rota. An exposure rate as low as one case per month for each clinician is quite likely.

\section{Conclusions}

From the published evidence there is no doubt that EPs, when appropriately trained, can carry out focused trauma ultrasound examinations with sensitivity and specificity comparable to that of trained sonographers and that, by extrapolation, this would also be the case for UK A\&E physicians.

I believe that in the UK, however, the additional training, quality assurance and maintenance of skills required by $A \& E$ physicians to perform this skill is not justified in view of the low frequency of presenting cases. Just because we can do it, does not necessarily mean that we should.

The author thanks Maralyn Woodford for her help with the retrieval of data from the UK Trauma Network Database.

Funding: none.

Conflicts of interest: none.

1 Nordenholz KE, Rubin MA, Gularte GG, et al. Ultrasound in the evaluation and management of blunt abdominal trauma. Ann Emerg Med 1997;29:357-66.

2 Rothlin MA, Naf RN, Amgwerd M, et al. Ultrasound in Rothlin MA, Naf RN, Amgwerd M, et al. Ultrasound in
blunt abdominal and thoracic trauma. $\mathcal{F}$ Trauma 1993;34: blunt abdo 95 .

3 Bode PJ, Neizen RA, Vugt AB, et al. Abdominal ultrasound as a reliable indicator for conclusive laparotomy in blunt abdominal trauma. F Trauma 1993;34:27-31.

4 Akgur FM, Tanyel FC, Akhan O, et al. The place of ultrasonographic examination in the initial evaluation of children sustaining blunt abdominal trauma. F Pediatr Surg 1993;28:78-81.

5 Liu M, Lee CH, P'eng FK. Prospective comparison of diagnostic peritoneal lavage, computed tomographic scanning,
and ultrasonography for the diagnosis of blunt abdominal trauma. F Trauma 1993;35:267-70.

6 Sarkisian AE, Khondkarian RA, Amirbekian MN, et al. Sonographic screening of mass casualties for abdominal and renal injuries following the 1988 Armenian earthquake. F Trauma 1991;31:247-50.

quake. F Trauma 1991;31:247-50.
7 Heller M. Emergency ultrasound: out of the acoustic shadows. Ann Emerg Med 1997;29:380-2.

8 Mateer J, Plummer D, Heller M, et al. Model curriculum for physician training in emergency ultrasonography. Ann Emerg Med 1994;23:95-102.

9 American College of Emergency Physicians council resolution on ultrasound. Irving: ACEP News, 1990

10 Society of Academic Emergency Medicine. Ultrasound position statement. Lansings, MI: SAEM Newsletter, 1991.

11 Porter RS, Nester BA, Dalsey WC, et al. Use of ultrasound to determine the need for laparotomy in trauma patients. Ann Emerg Med 1997;29:323-30.

12 Durham B. Emergency physicians saving time with ultrasound. Am F Emerg Med 1996;14:309-13

13 Steigler P. Ultrasound in the ED can mean faster diagnoses. ED Management 1995; July: 82-4.

14 Schlager D, Lazzareschi G, Whitten D, et al. A prospective study of ultrasonography in the emergency department by emergency physicians. Am $\mathcal{F}$ Emerg Med 1994;12:185-9.

15 Plummer D, Brunette D, Asinger R, et al. Emergency department echocardiography improves outcome in pendepartment echocardiography improves outcome in pen-

16 Mayron R, Gaudio FE, Plummer D, et al. Echocardiography preformed by emergency physicians: Impact on diagnosis preformed by emergency physicians: Impact

17 Sackett DL, Richardson WS, Rosenberg W, et al. Evidencebased medicine. How to practice and teach EBM. London: Churchill Livingstone, 1997:81-4.

18 Jehle D, Guarino J, Karamanoukian H. Emergency department ultrasound in the evaluation of blunt abdominal trauma. Am F Emerg Med 1993;11:342-6.

19 Ingeman JE, Plewa MC, Okasinski RE, et al. Emergency physician use of ultrasonography in blunt abdominal trauma. Acad Emerg Med 1996;3:931-6.

$20 \mathrm{Ma}$ OJ, Mateer JR, Ogata M, et al. Prospective analysis of a rapid trauma ultrasound examination performed by emergency physicians. $\mathcal{F}$ Trauma 1995;38:879-85.

gency physicians. F Trauma 1995;38:879-85.
$21 \mathrm{Ma}$ OJ, Mateer JR. Trauma ultrasound versus chest radiography in the detection of hemothorax. Ann Emerg Med 1997;29:312-16.

22 Shackford SR, Rogers FB, Osler TM, et al. Focused abdominal sonogram for trauma: The learning curve of Nonradiologist clinicians in detecting hemoperitoneum. $f$ Trauma 1999; 46:553-62.

23 Rozycki GS, Shackford SR. Trauma ultrasound for surgeons. In: Staren E, Arregui ME, eds. Ultrasound for the surgeon. Philadelphia, PA: JB Lippincott-Raven, 1996: 23-35.

24 American Institute for Ultrasound in Medicine. Official statement: training guidelines for physicians who evaluate and interpret diagnostic ultrasound examinations. Laurel, MA: American Institute for Ultrasound in Medicine, 1997.

25 Board of Faculty of Clinical Radiology. The Royal College of Radiologists. Guidance for the training in ultrasound of medical non-radiologists. London: The Royal College of Radiologists, 1997.

26 Bullock C. AIUM and SAEM square off over ultrasound. Emergency Medicine News 1993;15:1.

27 Lanoix R. Credentialing issues in emergency ultrasonography in the use of ultrasound in the emergency department. Emerg Clin North Am 1997;15:913-19. 